\title{
Interrogantes sobre producciones y publicaciones académicas en turismo
}

\author{
Questions on tourism academic production
}

\author{
Noemí Wallingre \\ Licenciatura en Turismo y Hotelería \\ Universidad Nacional de Quilmes, Argentina \\ nwallingre@unq.edu.ar \\ nwallingre@yahoo.com.ar
}

D esde las últimas décadas, los profesionales que se desempeñan en los ámbitos académicos, sin distinción disciplinar, están obligados, tal como expresa De Ambrosio (2018), a "publicar o perecer”, condición que les permitirá continuar o quedar fuera de ese sistema. Plantea que el clima de época fomenta lo irracional y una lógica orientada a la productividad -académica- a toda costa, incluso bajo riesgo de que los resultados sean débiles o erróneos, lo que deriva en una carrera encaminada hacia la cantidad y velocidad en que se produce; también a la superespecialización que, entre otros aspectos, debido a su enorme magnitud, impide estar al tanto de todo lo que se publica. Todo ello en desmedro de colocar el acento en la calidad y profundidad y en lograr aportes reales para que las publicaciones visualicen y contribuyan con el avance de los procesos educativos y científicos. Respecto de la hiperespecialización, Edgar Morín (1999), el padre de la teoría de la complejidad, permite reforzar que la misma impide ver tanto lo global (que fragmenta en parcelas), como lo esencial (que disuelve); además de tratar correctamente los problemas particulares que solo pueden plantearse y pensarse en un contexto, porque los problemas esenciales nunca son parcelados y los problemas globales son cada vez más esenciales.

De Ambrosio (2018) indaga sobre si los mecanismos indicados hacen que la ciencia funcione mejor, se explote todo el potencial creativo de las disciplinas, o si únicamente alimenta la máquina burocrática de producir papers o, quizá, solo sea una industrialización de la producción del conocimiento que genera cierto aburguesamiento que conspira contra las ideas creadoras; todo dependiente de un sistema de fondos, becas, subvenciones y ascensos en la carrera de investigador.

De esta manera, se transitan tiempos en los cuales quienes se dediquen a la investigación tienen que saber vender su idea y centrarse en la cantidad más que en la calidad de lo que producen y publican, hacerlo en tiempo récord y dentro de plazos cortos, muchas veces supeditados a las temáticas que requieren los sistemas de financiación (agencias gubernamentales, universitarias, privadas). Los científicos, y sus proyectos, son evaluados, básicamente, a partir de la cantidad de trabajos publicados y también por donde publican, ya que hay rankings de revistas de mayor o menor renombre o prestigio.

Para el caso de América Latina, Cantoral (2007) señala que, en la década de los setenta del siglo xx, las políticas universitarias latinoamericanas no planteaban a sus profesores 
la necesidad de publicar como requisito de permanencia, reconocimiento o promoción. En cambio, la universidad de los años ochenta, y sobre todo de los noventa, basó su modelo de desarrollo en la evaluación de los logros de los profesores, de los grupos de investigación y de los índices institucionales asociados con la productividad. El requisito para otorgar reconocimientos o promociones ha sido, desde entonces, fundamentalmente la publicación. Dice el autor que es así como en esos años se estableció la máxima: no hay nada peor que no publicar. Indica que, con los cambios en las formas de evaluar el mérito académico, se ha ido consolidando una nueva variante que apunta: sí hay algo peor que no publicar, es publicar y que nadie te lea (o te cite). Esta postura deja entrever que la región se adhiere a las tendencias y lineamientos globales vigentes.

\section{¿Y en el turismo cómo estamos?}

Si bien puede pensarse que las exigencias descritas recaen particularmente en quienes se dedican a investigar en el marco de las ciencias duras, tal situación se extiende, generaliza y comprende también a las ciencias humanas y sociales, y a aquellos campos de estudio de menor trayectoria en el tiempo, donde se incluye al turismo.

El estudio del turismo ha atravesado diferentes etapas evolutivas (desde finales del siglo XIX), así como distintas corrientes ideológicas y epistemológicas para su pensamiento -conviene resaltar que, al respecto, aún no existe un verdadero consenso-, que, sin duda, inciden en las temáticas de investigación y en las producciones académicas que se publican. Además, su abordaje científico transitó y transita los enfoques interdisciplinares, multidisciplinares o transdisciplinares, entre los cuales se entrelazan miradas encontradas con postulados más o menos favorables hacia uno u otro, dependiendo, en particular, de la formación disciplinar de quien se exprese.

De cualquier modo, todo ello ha contribuido a avanzar en la construcción del conocimiento del turismo, campo disciplinar que aún sigue siendo de desarrollo reciente respecto de otros más antiguos. Hay que rescatar que la búsqueda de la cientificidad del turismo continúa y permite despojar los estudios y los análisis de la subjetividad, de los preconceptos, de los mitos y hasta de la fantasía. Y porque, en todo caso, se puede generar conocimiento vulgar caracterizado por ser normalmente superficial, subjetivo y acrítico, a diferencia del conocimiento científico que es objetivo y reproducible (porque es un proceso que permite que otros investigadores arriben a iguales resultados) y sistemático (porque se trata de conocimientos ordenados lógicamente empleando procedimientos técnicos, que además deben contar con un método) (Schlüter, 2000).

Actualmente, y siguiendo los lineamientos globales, quienes se dedican a la investigación y al estudio del turismo quedan también comprendidos en los desafíos de publicar o desaparecer, y los sistemas universitarios y de investigación evalúan el desempeño de sus docentes-investigadores en gran parte a partir de su nivel de productividad en las publicaciones.

Ahora bien, en el turismo ¿qué tipo de investigación se produce y publica?: ¿fundamental o teórica, que propone nuevos conceptos y marcos referenciales? o ¿aplicada, más 
pragmática y empírica?; ¿sobre qué tipologías o temáticas se investiga y publica?; ¿la investigación que se realiza se focaliza en la calidad y profundidad de sus resultados?; ¿aporta verdaderos avances en los procesos científicos del turismo?

Al intentar dar respuesta a esos interrogantes, surgen puntos de vista diferenciales según los autores. Véanse solo algunos. Para Tribe (cit. en Panosso Netto, 2011), existen tres temáticas claras de investigación en turismo: los negocios, las ciencias sociales y la crítica. Castillo Nechar y Panosso Netto (2010), basados en otros autores, observan que un alto porcentaje de los estudios en turismo son descriptivos, de estadística descriptiva, de corte económico y de impactos socioculturales, los que prevalecen por sobre los de carácter académico (teórico-conceptual). Tribe distingue además dos grupos muy claros en la investigación del turismo: los interesados en las cuestiones empresariales del turismo y los interesados en cuestiones no empresariales (ambientales, sociales u otras). César Dachary (2005) focaliza los referentes de la investigación contemporánea en turismo en los cambios de la sociedad y el trabajo, en las nuevas dimensiones del tiempo y el espacio, en las nuevas tecnologías y la magia del turismo, en el turismo como modelo de desarrollo y de recolonización, en una nueva geografía del turismo, en el ambiente y las nuevas opciones del turista y la cultura. Cuando alude a las tipologías de su investigación rescata, por un lado, los estudios micro, incluyendo como temas particulares los del mercado-perfil del turista; como temas vinculados al turismo, los impactos y la contaminación, y los temas compartidos con el turismo como la moda y la seguridad. Por otro lado, los estudios macro, diferenciándolos, según el universo, en corredor, país, región, comarca; según el proceso, en transición de zonas aisladas o marginales, creación de polos; según el tema dominante, en naturaleza, historia, cultura; según la estrategia de desarrollo, en sustentable, viable económicamente; y, según el mundo, en rural o urbano.

Por su parte, Pearce (2003) plantea que la mayoría de las orientaciones adoptadas en la investigación turística no está vinculada entre sí (anteriores y actuales), dando lugar a una producción muy atomatizada; la mayor parte fue realizada en forma individual o en pequeños equipos (limitadas competencias y recursos) centrándose en sectores específicos (transporte, alojamiento, atractivos, demanda, otros); se produjo muy poca investigación sistemática (que comprenda múltiples aspectos y dimensiones) y atrajo investigadores de una gran variedad de disciplinas, así como también que hay poca investigación multidisciplinar. Cuando se refiere a las orientaciones futuras de la investigación del turismo, alude a las tendencias de una mayor dispersión geográfica de los nuevos destinos, muchos en desarrollo y otros en franco crecimiento, lo cual concibe nuevos temas a investigar y cree, por lo tanto, que son necesarias nuevas preguntas que permitan orientarlos. Sostiene que las posibles respuestas estarán producidas con mayor claridad en la dirección a seguir y sustentada en la pregunta ¿cómo se logra?, y ensaya tres posibilidades: la amplitud geográfica (enfoques supranacionales, nacionales, regionales, locales), la integración de los marcos de actuación (claros y analíticos que permitan soluciones más integradas) y los desarrollos teóricos y metodológicos (generar bases conceptuales -teoría y método-). 
Para Ortega, Rodríguez y Cobo (2003), la investigación del turismo se viene realizando desde hace mucho tiempo por diferentes instituciones, asociaciones o empresas vinculadas con la actividad. La menos conocida es la promovida por las empresas, porque no tiene por finalidad ser difundida, sino constituirse en el motor para obtener un conocimiento propio que les permita adoptar acciones o estrategias futuras; en cambio, la que tiene su origen en las instituciones (universitarias, asociaciones, otras) está más abierta a la difusión.

Esta última perspectiva alude a que la investigación no necesariamente debe concentrarse en los niveles académicos; más bien hay que reconocer el conocimiento tácito producido por las empresas, la administración pública, las organizaciones no gubernamentales y los centros independientes que pueden incorporar diversos intereses y, por lo tanto, los temas de investigación variarán dependiendo de quienes los promuevan y realicen. Sin embargo, la construcción ideológica y epistemológica tiene su centro en los ámbitos y niveles académicos y es desde donde se genera la mayoría de las publicaciones. Dicho de otro modo, la transferencia del conocimiento construido se realiza desde estos últimos.

Otra aportación a tener en cuenta es que mayoritariamente las publicaciones en turismo, por lo menos en Latinoamérica, se sostienen en la investigación empírica y basada en análisis de casos, en general de pequeña escala (territorial, empresarial, gubernamental), y son muy escasos los aportes teóricos y metodológicos. Además, en muchas oportunidades, es posible observar determinadas inconsistencias o falta de solidez metodológicas en su desarrollo. A su vez, los aportes son producidos por profesionales de una enorme diversidad de disciplinas - que abarcan desde la economía hasta la antropología, por citar dos extremos-, cada uno de los cuales realiza un abordaje a partir de su formación de grado desde donde orienta la investigación, y desde un desconocimiento generalizado de las reales construcciones, complejidades y conceptos del turismo. Por lo tanto, sus resultados son influenciados por otros campos disciplinares que imposibilitan captar la complejidad del tejido del turismo en su conjunto.

\section{Una mirada futura sobre las producciones y publicaciones académicas en turismo}

Retomando a De Ambrosio (2018) sobre su postura sostenida en la necesidad de "publicar o perecer", este plantea que, en el ámbito universal, se está intentando buscar otras opciones, al punto de proponerse una llamada "ciencia lenta" (slow science) impulsada por algunos filósofos y emparentada con otros fenómenos slow vigentes en el mundo. Tiende, según el autor, a que la producción científica deje de lado la búsqueda de resultados cuantitativos y tenga una visión más macro del para qué se hace ciencia, quién usará los resultados en cada caso y con qué intencionalidad. Para esta perspectiva, de lo que se trata es que los procesos científicos sean políticos, en el mejor sentido de esa palabra, y que la creatividad se libere de las presiones productivistas. El autor cita al biólogo e investigador 
Alberto Kornblihtt, quien pone el énfasis en lo que debiera ser la base de toda práctica científica: curiosidad y libertad, y explica que la misión de un científico es investigar sobre la base de preguntas que no han sido aún respondidas, para obtener hallazgos y nuevas conclusiones. Entiende que, en este proceso, es necesario hacer públicas las conclusiones para que otros científicos las lean, las verifiquen, las comenten, las refuten, las critiquen. 0 se inspiren para iniciar o continuar sus propias investigaciones. Es decir: publicar debe ser la consecuencia de haber encontrado algo, y no un fin en sí mismo.

Desde este interesante planteamiento, y retomando algunos interrogantes ya expuestos, en el campo de estudio del turismo es pertinente indagar sobre:

- $\quad$ si se está haciendo ciencia teórica o aplicada;

- qué temáticas se están produciendo y publicando;

- qué tipo de artículos o textos se escriben y publican (investigación, didácticos, ensayos, revisión);

- si se conoce lo que otros profesionales están publicando, en particular sobre la temática que es de nuestro interés;

- si cuando se cree que se está innovando, se verifica que no se esté repitiendo a otros autores;

- si las producciones que se publican contribuyen a mejorar/ampliar los procesos de enseñanza-aprendizaje y la investigación; si permiten la transferencia a las organizaciones empresariales, gubernamentales, y a la sociedad en su conjunto;

- si se producen nuevos desarrollos teóricos, métodos y nuevas técnicas para apuntalar los avances;

- si prevalece la calidad y la profundidad de los resultados por sobre la cantidad.

Tender hacia una sólida construcción en el avance de la investigación en turismo continúa siendo una necesidad porque es un pilar fundamental para fortalecer no solo el campo disciplinar sino también la actividad. Además, hay que preguntarse sobre qué tipo de artículos priorizan en sus publicaciones las revistas académicas especializadas en turismo; si son equitativas en sus elecciones, si se valora la calidad y profundidad de los resultados. Otra preocupación que se presenta es si no se estará -de tanto privilegiar las publicaciones en papers- descuidando las publicaciones de buenos libros de textos que históricamente han nutrido -y deberían seguir haciéndolo- los procesos integrales de enseñanza-aprendizaje, y de la investigación del turismo.

Asimismo, desde los ámbitos académicos se debe tener presente que no solo hay que investigar para instrumentar la realidad (mercado y Estado), sino también con el propósito de construir bases sólidas para una epistemología del turismo. Como la investigación aplicada prevalece ampliamente por sobre la investigación teórica en cuanto generadora de ideas o teorías, esta última debería tener una mayor promoción institucional.

Para finalizar, es pertinente buscar respuestas a los interrogantes planteados y, de ser necesario, revisar y redefinir el camino transitado para que permita construir una visión de 
futuro en concordancia con los desafíos que en el campo de estudio del turismo se presentan. De lo contrario, no se legarán grandes y nuevas contribuciones, y solo se seguirá cumpliendo con los parámetros cuantitativos de producción que las distintas organizaciones requieren.

\section{Fuentes consultadas}

Ambrosio, M. de. (11 de marzo de 2018). La ciencia, víctima del "publicar o perecer". La Nación. Recuperado de https://www.lanacion.com.ar/2115347-la-ciencia-victima-del-publicar-o-perecer

Cantoral, R. (Noviembre, 2007). ¿Publicar o perecer, o publicar y perecer? Relime, 10(3), 311-313.

Castillo Nechar, M. y Panosso Netto, A. (2010). Epistemología del turismo. Estudios críticos. México: Trillas.

César Dachary, A. (2005). La construcción del paradigma del turismo: un camino interdisciplinario. Congreso La creatividad en el turismo para el nuevo milenio [CD]. Universidad Nacional del Comahue, Neuquén.

Morín, E. (1999). Los siete saberes necesarios para la educación del futuro. Buenos Aires: Ediciones Nueva Visión.

Ortega, E., Rodríguez, B. y Cobo, F. (2003). La investigación del turismo a través de las tesis doctorales. Un análisis comparativo entre España, Estados Unidos y Francia. En E. Ortega (coord.), Investigación y estrategias turísticas (pp. 65-90). Madrid: Thomson.

Panosso Netto, A. (2011). Filosofía do turismo. Teoría e epistemología (2 ${ }^{a}$ ed.). São Paulo: Aleph.

Pearce, D. (2003). Orientaciones actuales y futuras en la investigación turística. En E. Ortega (coord.), Investigación y estrategias turísticas (pp. 91-106). Madrid: Thomson.

Schlüter, R. (2000). Investigación en turismo y hotelería. Buenos Aires: Centro de Investigaciones y Estudios Turísticos. 